\title{
Design of a load carriage system oriented to reduce acceleration forces when carrying a backpack
}

\author{
Diseño de sistema de carga orientado a disminuir fuerzas de aceleración al portar un morral
}

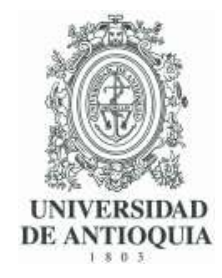

\author{
Camilo Eduardo Pérez-Cualtán (iD ${ }^{1 *}$ Oscar Iván Campo-Salazar (iD) 1 \\ ${ }^{1}$ Departamento de Automática y Electrónica, Facultad de Ingeniería, Universidad Autónoma de Occidente. Calle 25 \#115-85. C. P. 760026. \\ Cali, Colombia.
}

\section{CITE THIS ARTICLE AS:}

C. E. Pérez, O.I. Campo.

"Design of a load carriage

system oriented to reduce

acceleration forces when

carrying a backpack", Revista

Facultad de Ingeniería

Universidad de Antioquia, no.

95, pp. 34-43, Apr-Jun 2020.

[Online]. Available: https:

//www.doi.org/10.17533/

udea.redin. 20190734

\section{ARTICLE INFO:}

Received: March 22, 2019

Accepted: July 19, 2019

Available online: July 19, 2019

\section{KEYWORDS:}

Biomechanics; backpack; suspended load

Biomecánica; morral; carga suspendida
ABSTRACT: In military life, load carriage is an unavoidable part of field operations which is the reason why soldiers often make use of a military backpack. Infantry soldiers usually carry loads weighting more than $30 \%$ of their body weight. When the soldier carries a certain weight, his energy expenditure increases, which causes a reduction in performance. The transported load has a movement similar to the vertical displacement of the center of mass of the soldier while walking. This leads to a significant increase in the acceleration forces generated by the action of said load on the body which explains the increase in energy expenditure. The objective of this project was to develop a load carriage system that suspends the load and reduces its vertical displacement. Results show a reduction in both the vertical excursion of the load and in the total vertical ground reaction force when carrying a load with the developed prototype, with respect to the conventional military backpack.

RESUMEN: En la vida militar, el transporte de cargas es una actividad inevitable durante operaciones de campo, razón por la cual los soldados hacen uso de un morral militar. Los soldados de infantería generalmente transportan cargas mayores al $30 \%$ de su peso corporal. Cuando el soldado transporta una carga, su gasto energético aumenta lo que ocasiona una reducción en su rendimiento. La carga transportada tiene un movimiento similar al desplazamiento vertical del centro de masa del soldado durante la marcha. Esto conlleva a un aumento significativo de las fuerzas de aceleración generadas por la acción de la carga sobre el cuerpo lo que explica el aumento del gasto energético. El objetivo del proyecto fue desarrollar un sistema de transporte de carga que la mantenga suspendida para así reducir su desplazamiento vertical. Los resultados muestran una reducción tanto en la excursión vertical como en la fuerza vertical total de reacción del suelo al transportar una carga con el prototipo desarrollado, respecto al morral militar convencional.

\section{Introduction}

The members of the military forces constantly need to transport supplies, equipment, personal items, ammunition and clothing in training or field operations. This is an inevitable part of the everyday life of military troops. Infantry soldiers resort to military backpacks attached to a structure which serves as a load carriage system, often transported in the vehicle trunk [1].

The magnitude of the load generated by the weight

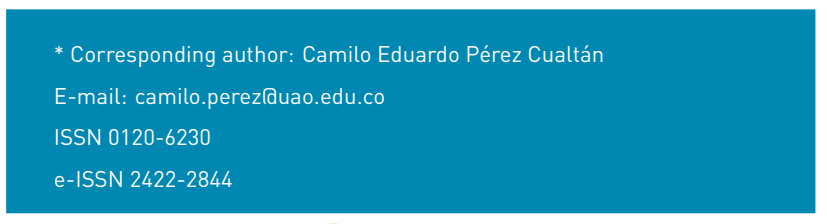

carried by soldiers in their backpacks is significant [2]. The ground reaction forces increase as the weight of the carried load increases. The components that are most affected during the transportation of heavy loads are the Vertical Ground Reaction Force (VGRF) and the antero-posterior ground reaction force. The literature suggests that, at a constant walking speed, both peaks of VGRF curve increase in direct proportion to the weight of the load lof up to $50 \mathrm{~kg}$ ) and some studies suggest that the VGRF increases approximately $10 \mathrm{~N}$ for every kilogram of additional external load [3]. Furthermore, the extensive time spent carrying the load, in addition to the irregular terrains travelled and harsh climatic conditions, all contribute to affecting the musculoskeletal system of soldiers at a physiological and biomechanical level [1]. As 
a consequence, there is a significant increase in energy expenditure [4-6].

Movement during walking is the product of forces or energy transfers that originate intrinsically and extrinsically. The Center of Mass (COM) of the body during walking, is characterized by having a non-rectilinear movement, yet it describes vertical and horizontal displacements, which lead to an increased metabolic expenditure. To improve gait performance, energy transfers are produced. The amplitude of the vertical displacement of the soldier COM while walking is close to $5-7 \mathrm{~cm}$ and is reflected in the military backpack thus describing a similar vertical displacement [4]. Said displacement results in an increase of the acceleration forces generated by the action of the load on the body. These forces can reach up to twice of those imposed by static weight, due to the acceleration of added masses. This causes a considerable increase in energy expenditure for the soldier carrying the load [6].

A new invention was introduced a few years back, which is called the suspended-load backpack, that reduces the vertical movement and forces generated by the load on the carrier leading to energetic benefits [7]. Some research groups have designed different concepts for suspension systems to be used in suspended-load backpacks. Results vary according to the mechanical parameters of suspension, the walking speed and the weight of the load. In some cases, there is a reduction in energy expenditure and acceleration forces [7] when transporting a military backpack and others show an increase [8].

In this research, a load carriage system with mechanical suspension was designed to reduce the vertical excursion of the COM of the load. The requirements of Colombian infantry soldiers are considered while maintaining a simple and economical design. The objective of the project was to develop a load carriage system with load suspension that reduces the vertical displacement of the backpack, thereby diminishing the acceleration forces acting on the soldier, in order to reduce the acceleration forces. The mechanical suspension of the system was simulated, a CAD model was designed, and a prototype version of the load carriage system was subsequently implemented. Experimental tests were carried out to validate the performance of the developed prototype and a pilot test was performed on Colombian military forces to assess the effect of the load carriage system in terms of kinetic parameters.

\section{Design and methods}

\subsection{Suspension design and model}

The vertical displacement of the COM of a person while walking can be approximated to a sinusoid with fixed frequency and amplitude [9]. To determine the suspension values of the load carriage system, the two-degree-of-freedom theoretical model proposed by [10] was used since the simulation results were strongly correlated with the experimental measurements. The model simulates the vertical displacement of the centers of mass of the carrier and the load, as illustrated in Figure 1. The model helps to determine the optimum coupling of the load (mass 2 denoted M2) with the COM of the carrier (mass 1 denoted $\mathrm{M} 1$ ). The model shows reduced peaks in the resulting forces and a reduction in energy consumption while walking.

Initially, [11] built a physical model of a suspended-load backpack to assess the kinetic and time-space effects. The prototype was built $(6.7 \mathrm{~kg})$ with four springs (elastic constant of $4026 \mathrm{~N} / \mathrm{m}$ ) for load oscillation, yet its damping coefficient was unknown. Subsequently [8] determined the mechanical characteristics of a conventional backpack and the influence of a load-suspended backpack while walking. It was concluded that any resonance effect between both movements can lead to a modified gait pattern and an increase in the forces generated by the load. Taking into account that previous research shows either increased or reduced energy expenditure when transporting a load in a backpack, [10] generated a spring-mass-damping model with two-degree-of-freedom to simulate a person walking while carrying a load. The developed model represents a system that vertically oscillates in place with a sinusoidal pattern. The length of the leg $(U)$ in contact with the ground varies similarly to the theoretical models of inverted pendulum.

The equations of motion for the dynamic system shown in Figure 1 are detailed down below. An initial analysis of free body was carried out. Then, the state variables of the system are declared to establish their derivatives depending on said variables as well as the system input $(U)$. Equation 1 represents the vertical displacement of the center of mass of the carrier (X1) and Equation 2 represents the vertical displacement of the center of mass of the load (X2). $K$ denotes the suspension stiffness and $B$ denotes the suspension damping. Based on the previous equations, the equation of state of the dynamic system is defined as seen in Equation 3. After replacing Equations 1 and 2, Equation 4 is obtained. 


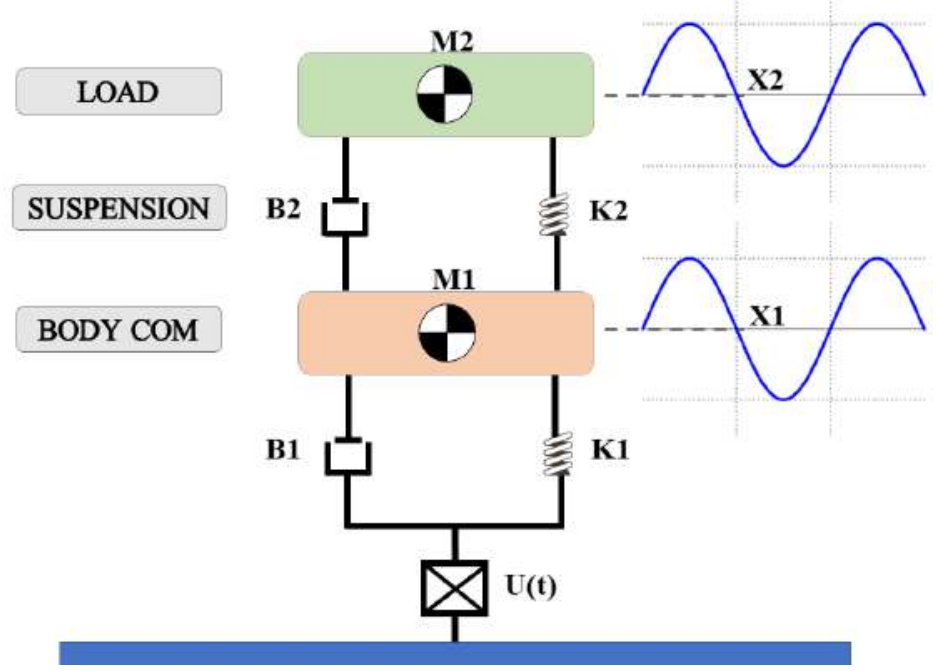

Figure 1 Double-mass coupled oscillator model used to approximate the vertical displacement of the center of mass with an added load while walking

For $M_{1}$ (body center of mass):

$$
\begin{gathered}
\ddot{X}_{1}=\frac{K_{1} U(t)}{M_{1}}+\frac{B_{1} U(t)}{M_{1}}-\frac{\dot{X}_{1}\left(B_{2}+B_{1}\right)}{M_{1}}-\frac{X_{1}\left(K_{2}+K_{1}\right)}{M_{1}} \\
+\frac{K_{2} X_{2}}{M_{1}}+\frac{B_{2} \dot{X}_{2}}{M_{1}}
\end{gathered}
$$

For $M_{2}$ (mass of the load)

$$
\ddot{X}_{2}=-\frac{K_{2} X_{2}}{M_{2}}+\frac{K_{2} X_{1}}{M_{2}}-\frac{B_{2} \dot{X}_{2}}{M_{2}}+\frac{B_{2} \dot{X}_{1}}{M_{2}}
$$

Equation of the state of the dynamic system:

$$
\begin{gathered}
\dot{x}=a x+b u \quad ; \quad y=c x \\
r\left[\begin{array}{c}
\dot{x}_{1} \\
\dot{x}_{2} \\
\dot{x}_{3} \\
\dot{x}_{4}
\end{array}\right]=\left[\begin{array}{cccc}
0 & 1 & 0 & 0 \\
-\frac{K_{2}+K_{1}}{M_{1}} & -\frac{B_{2}+B_{1}}{M_{1}} & \frac{K_{2}}{M_{1}} & \frac{B_{2}}{M_{1}} \\
0 & 0 & 0 & 1 \\
\frac{K_{2}}{M_{2}} & \frac{B_{2}}{M_{1}} & -\frac{K_{2}}{M_{2}} & -\frac{B_{2}}{M_{2}}
\end{array}\right] \\
\\
{\left[\begin{array}{c}
X_{1} \\
X_{2} \\
X_{3} \\
X_{4}
\end{array}\right]+\left[\begin{array}{c}
0 \\
\frac{K_{1}}{M_{1}}+\frac{B_{1}}{M_{1}} \\
0 \\
0
\end{array}\right] u}
\end{gathered}
$$

The values of parameters $M_{1}$ (main mass), $K_{1}$ (rigidity of the leg), and $B_{1}$ (cushioning of the leg) are approximations to the values of an average human being. The oscillation amplitude of the actuator of the leg has a fixed value. The model has the same values as those used by [10], who conclude that the energy expenditure is reduced when the natural frequency of load suspension $\left(W_{d}\right)$ is much lower than the walking frequency $\left(W_{f}\right)$ as seen in Equation 5, because of its behavior as a vibration isolator. Hence, the movement of the load is decoupled from the movement of the body's COM during the act of walking.

$$
W_{d}=\sqrt{\frac{K 2}{M 2}} \ll W_{f}
$$

\subsection{Characterization of the suspension}

The designed suspension differs from other types of suspension which have been used in suspended-load backpack systems. The proposed suspension system contains a gas damper and spring working in parallel. The elastic constant of suspension $(1000 \mathrm{~N} / \mathrm{m})$ was determined for the springs through simple static tests. For the characterization of the damping coefficient (B) of the suspension, a $16 \mathrm{~kg}$ mass was suspended with an elastic constant of $4185 \mathrm{~N} / \mathrm{m}$. An experimental test was carried out to determine the position ( $\mathrm{x}$ ) of a mass (M) defined as a time function that receives a step input. The damping coefficient of suspension is derived from such experiment.

The tests were performed with the motion sensor $\left(P A S C O^{\circledR}\right)$ at a sampling frequency of $100 \mathrm{~Hz}$. The results were subsequently processed and optimized in order to determine the damping factor $(\delta)$ of the mechanical suspension as shown in Figure 2. This leads to results similar to previous studies $[11,12]$.

Experimental data show an underdamped behavior $(\delta<1)$ [13]. Two methods to calculate $\delta$ were used, one theoretical and one by means of an optimization model, the two methodologies were compared with the experimental data, and the graphs were contrasted point by point using the square root of the mean quadratic error or RMSE to determine which methodology had the 


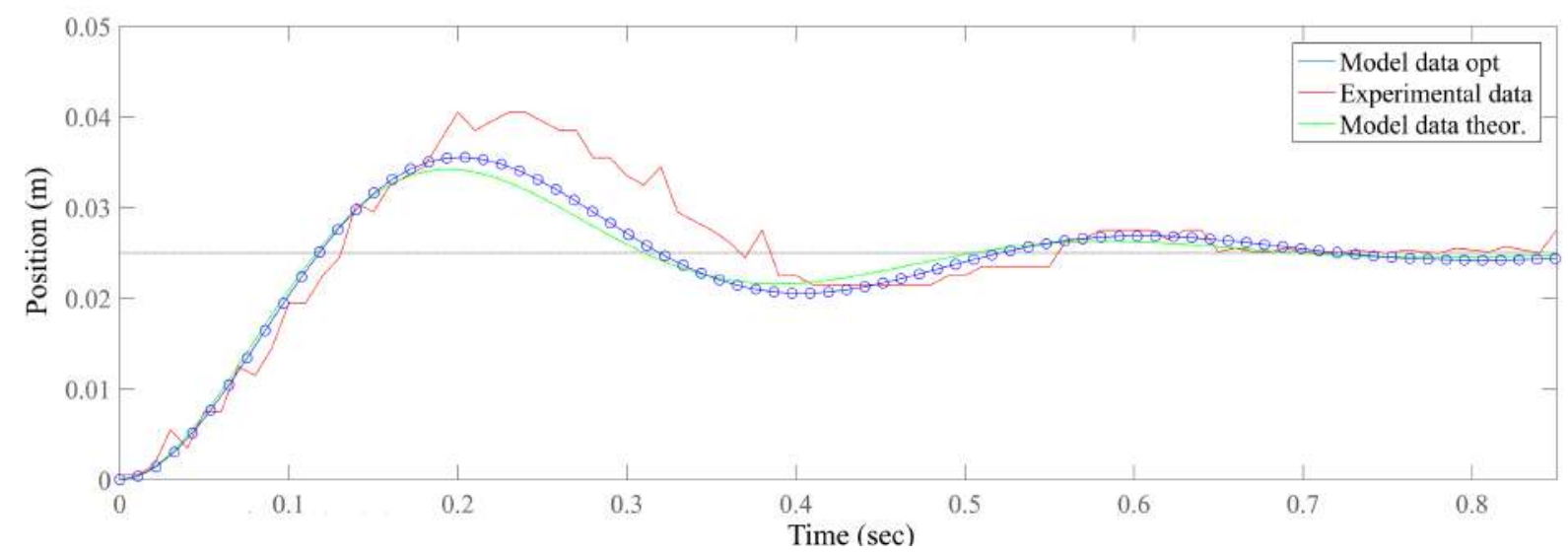

Figure 2 Simulation and experimental data obtained from mechanical suspension

least error with respect to the data, as shown in Table 1. Once the pneumatic damping coefficient was found, the vertical excursion of the mechanical suspension system was determined through the [10] model, a block diagram was constructed using the equation of states (Equation 4) in Simulink Matlab ${ }^{\circledR}$, to plot the behavior of the load during walking fulfilling the characteristic of the Equation 5 as shown in Figure 3, where the natural frequency is much lower than the walking frequency, which decreases the amplitude of the vertical excursion of the load.

Table 1 Mechanical characterization of the damper

\begin{tabular}{lccc}
\hline METHOD & $\begin{array}{l}\text { DAMPING } \\
\text { FACTOR }(\boldsymbol{\delta})\end{array}$ & $\begin{array}{l}\text { DAMPING } \\
\text { COEFFICIENT } \\
(\mathrm{B})\end{array}$ & RMSE \\
\hline $\begin{array}{l}\text { Theorical } \\
\text { Model } \\
\begin{array}{l}\text { Optimization } \\
\text { Algorithm }\end{array}\end{array}$ & 0.3018 & 156 & 0.0186 \\
\hline
\end{tabular}

\subsection{Design of the device}

Once the mechanical characteristics of the suspension were determined and the discussed model was simulated, a CAD (computer aided design) version of the load carriage system was designed (Figure 4), which was then physically implemented for a pilot test. The said system considers the anthropometric measurements of the average Colombian male between 20 and 29 years of age, serving as guidelines for the dimension of the structure [14]. Six anatomic parameters of the trunk were determined to design the structure, similar to those proposed by [15] where a dummy was generated with the anthropometric measurements guide, to have a design base for an ergonomic to the Colombian soldier.

The system consists of three frames lone is fixed and two are mobile), which are coupled to a mechanical suspension through coupling parts in charge of reducing the vertical displacement of the load. The backpack fits into the mobile frames while the fixed frame fits with the trunk of the soldier.

For the assignment of CAD materials, polymers (PLA 3D printing and Polypropylene) were used to manufacture the structure. In addition to an analysis of finite elements (AFE) carried out in Solidworks ${ }^{\circledR}$, a static analysis was simulated for the structure with a $300 \mathrm{~N}$ load that exceeds the maximum magnitude set in vertical direction to the ground for static analysis as shown in Figure 5. The frames were assigned as Polypropylene, (Density: $933 \mathrm{~kg} / \mathrm{m}^{3}$; Young's Modulus: $1.79 \mathrm{GPa}$; Tensile Strength, Yield: 33 $\mathrm{MPal}$ and the coupling parts were assigned as PLA for 3D printing (Density: $1250 \mathrm{~kg} / \mathrm{m}^{3}$; Young's Modulus: $3 \mathrm{GPa}$; Tensile Strength, Yield: $49.5 \mathrm{MPa}][16,17]$, which couple the fixed frames and suspension.

The greatest effort of the structure was detected in the coupling pieces of the mobile frame placed in the $90^{\circ}$ edge. Since the load is of the cutting type, a support was added to help reduce effort. The efforts and tensions that act on the system are significantly low, and the minimum safety factor of the structure was 35 as shown in Figure 6 and 7. Once the AFE was carried out, the pieces were manufactured with the previously assigned materials by rapid prototyping techniques, subsequently, all the parts were assembled, and the prototype was ready to perform experimental tests (Figure 8). The methodology used is described in the block diagram of Figure 5.

\subsection{Experimental test}

A functional alpha prototype of the system was built through fast prototyping, that could carry out experimental tests and study the response of the developed system. The VGRF is the strongest force bestowed by the ground on the 


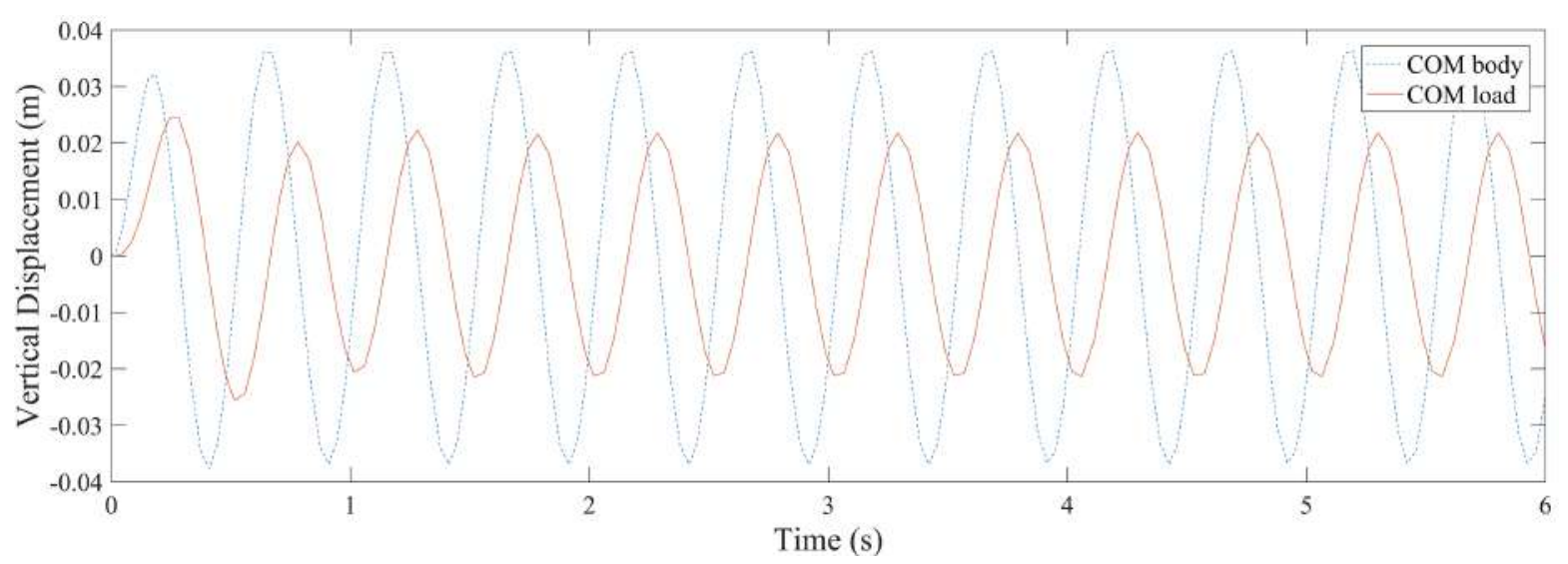

Figure 3 Dynamic response of the model used for $\mathrm{M} 2=25 \mathrm{~kg}, \mathrm{~K} 2=1000 \mathrm{~N} / \mathrm{m}$ and $\mathrm{B} 2=138 \mathrm{Ns} / \mathrm{m}$

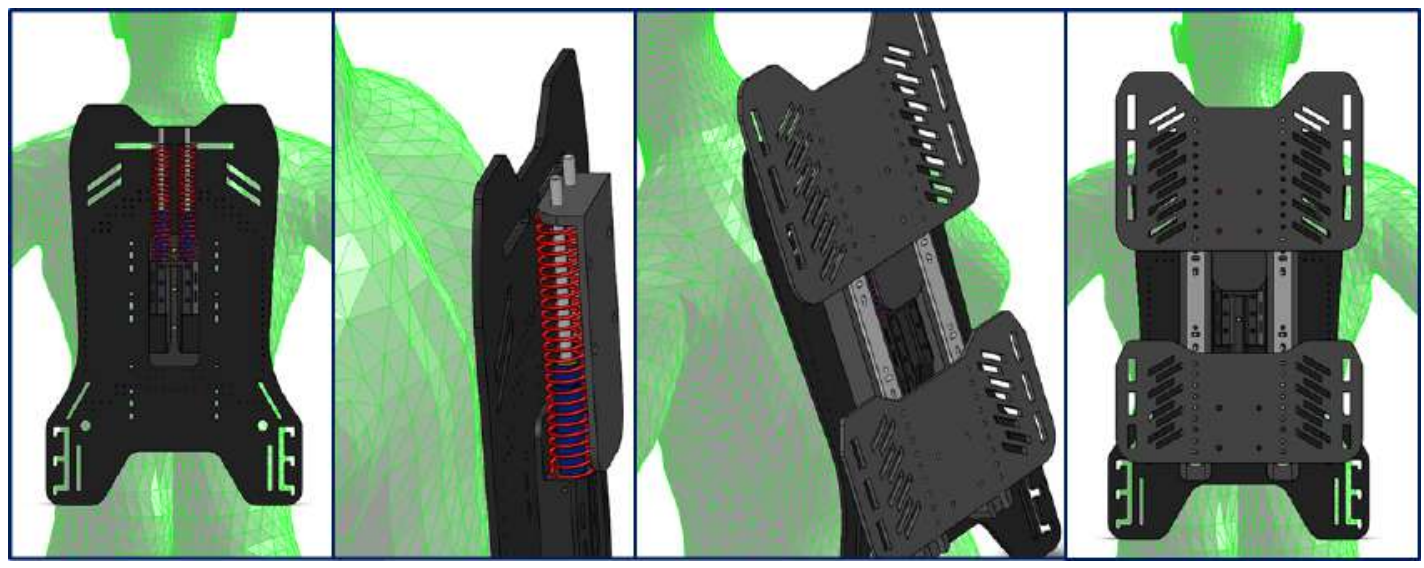

Figure 4 CAD model of the load carriage system. Side and front view

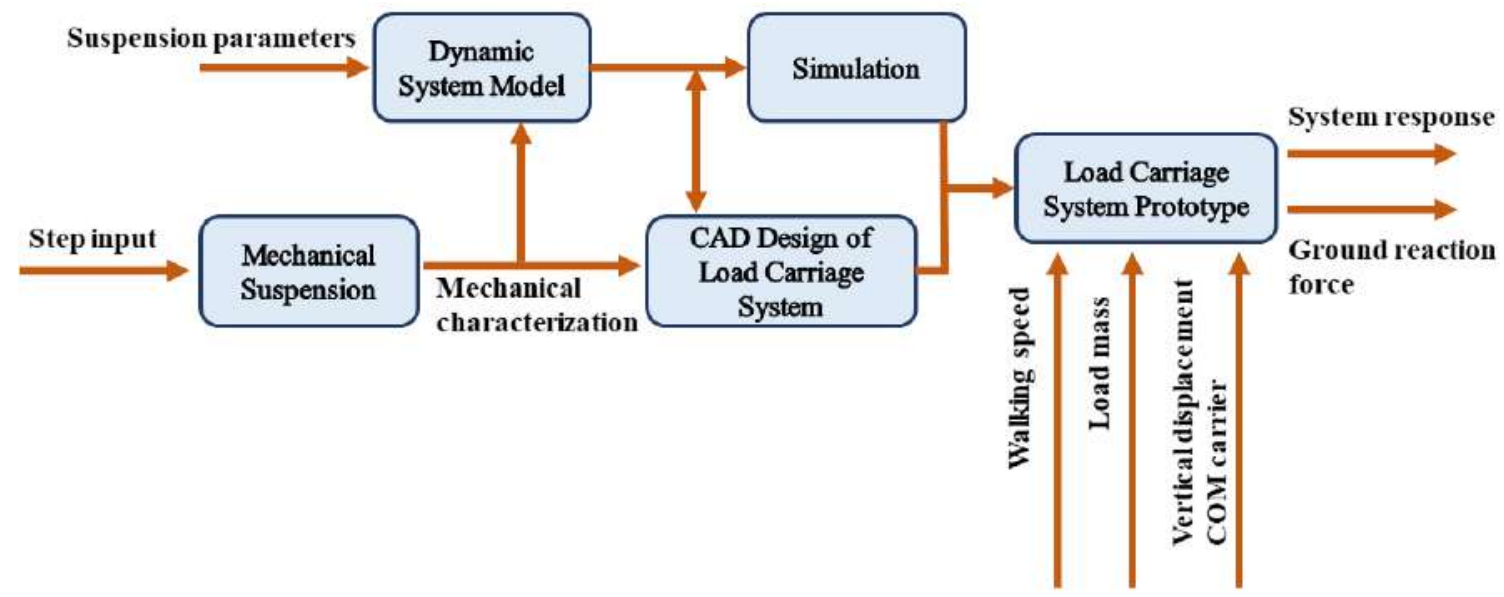

Figure 5 Development methodology of the project

body which translates into vertical displacements of the center of gravity. Being one of the most affected forces during load transportation [18], it was decided to measure the GRF to see the response of the developed system.

Four male participants from the Military School of
Aviation Marco Fidel Suárez were evaluated. The group of participants had no cardiovascular pathologies nor any type of musculoskeletal injury over the last two months. The average and standard deviation (SD) values of age, height and weight were $20.75 \pm 3.6$ years, $1.68 \pm$ 0.08 meters and $67.9 \pm 9.38$ kilograms respectively. 


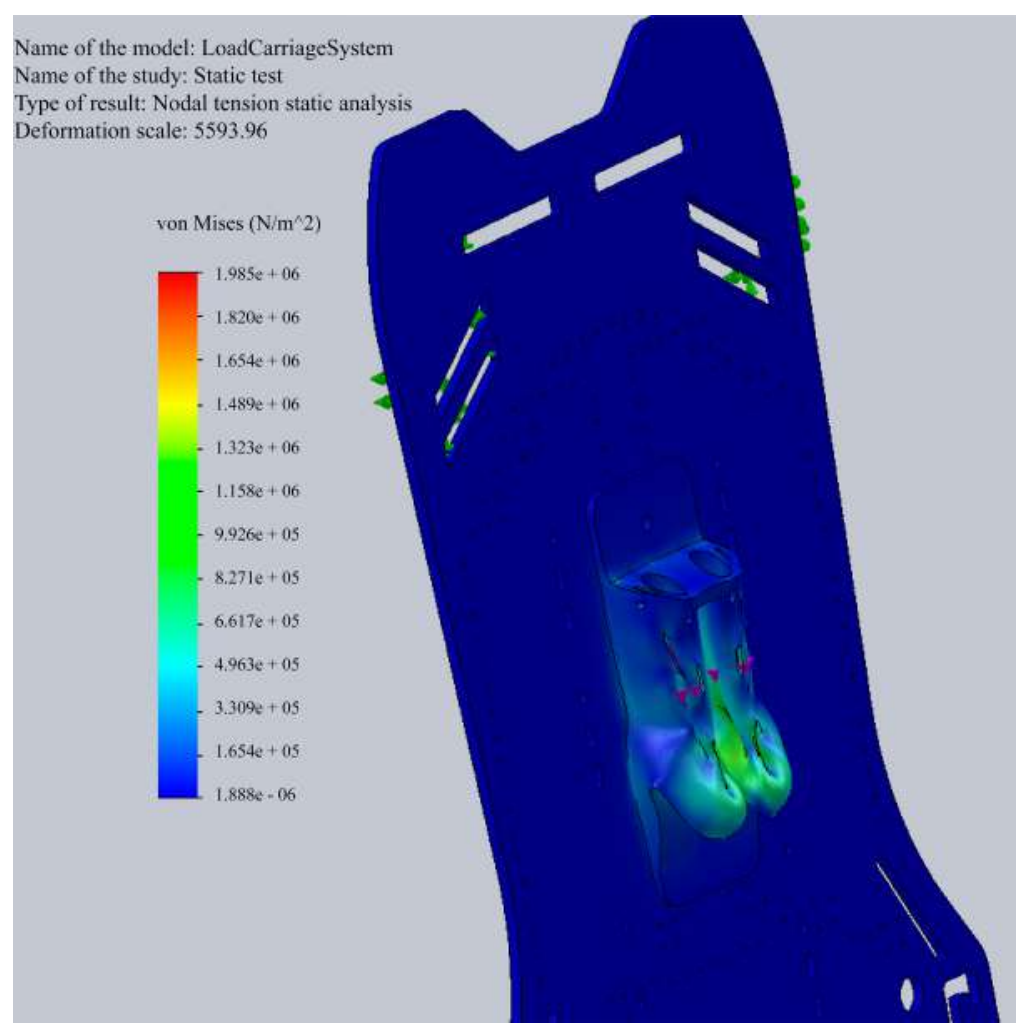

Figure 6 Von Misses Tensions of the structural coupling parts

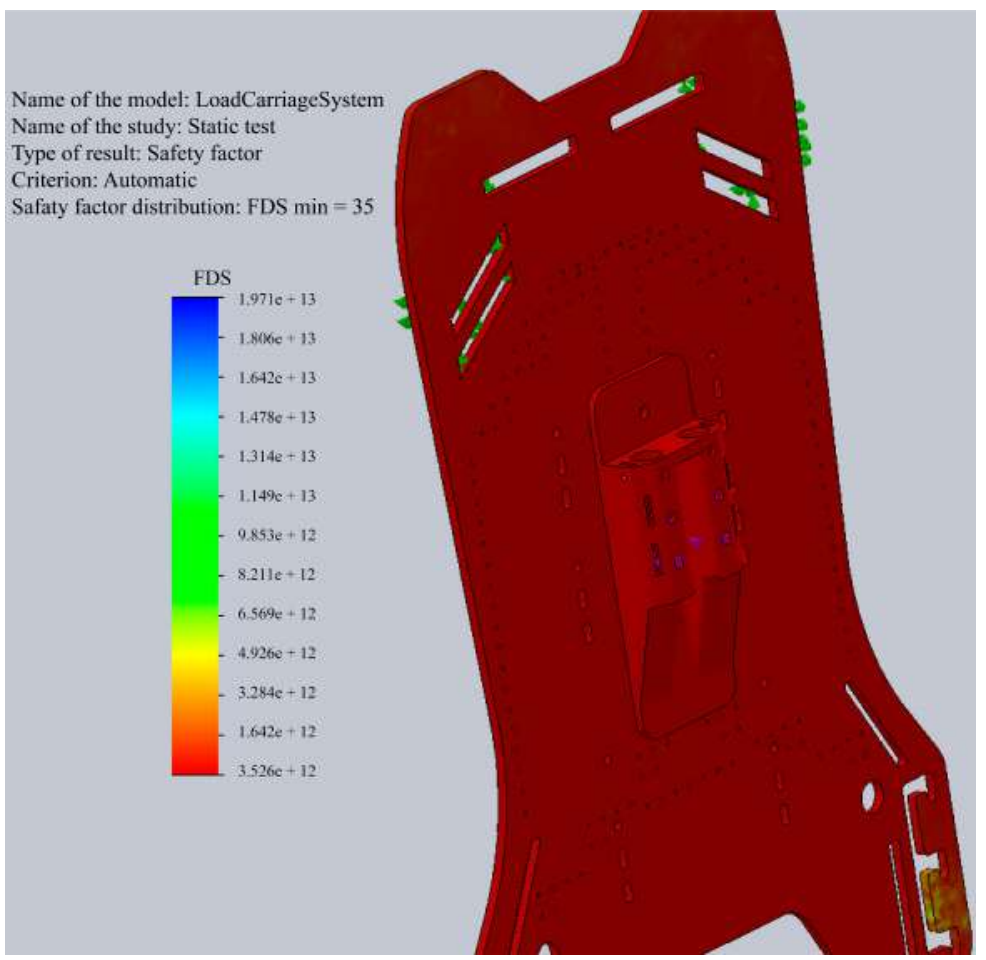

Figure 7 Safety factor of the structure

Participants were assessed in the Biomechanics Laboratory of Universidad Autónoma de Occidente in
Cali (Figure 9). The movement of the load was recorded on video at $2 \mathrm{k}$ a $60 \mathrm{fps}$ in one subject, in order to track 


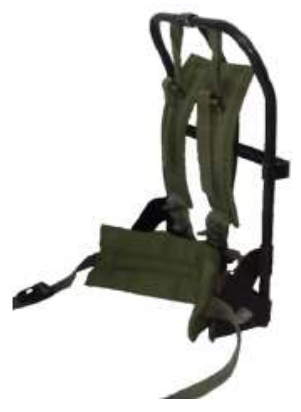

(a) A. Structure of a conventional military backpack in Colombia and B. Structure of the load carriage system prototype

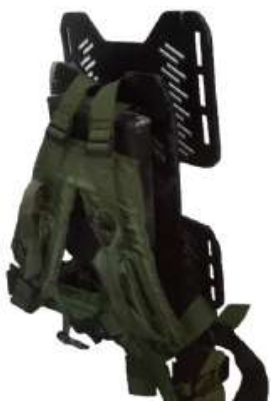

(b) Structure of the load carriage system prototype

Figure 8

it through video motion analysis before measuring the VGRF. The treadmill was set at a constant speed while the masses were varied.

To determine the ground reaction forces, two KISTLER ${ }^{\circledR}$ force plates placed on the ground were used and the sampling frequency was set at $400 \mathrm{~Hz}$ to capture data with the force platforms. The experiments involved three scenarios:

- Walking without load.

- Walking with the traditional load system used by Colombian soldiers (the carried mass weighted $20 \mathrm{~kg}$ ).

- Walking with the load carriage system prototype lthe carried mass weighted $20 \mathrm{~kg}$ ).

The participants had to walk on the force platforms at an average speed of $1.55 \pm 0.2 \mathrm{~m} / \mathrm{s}$. To measure the walking speed of the soldiers, a metronome with a 121 BPM frequency $(2.021 \mathrm{~Hz})$ was used.

\section{Results}

The military backpack was initially attached to the mobile frames of the prototype thus adding masses of different weights: $18.5,20$ and $22.25 \mathrm{~kg}$, which were recorded on video. The response of the prototype was assessed on a subject moving at $1.5 \mathrm{~m} / \mathrm{s}$ (Figures 10-11). Finally, tests

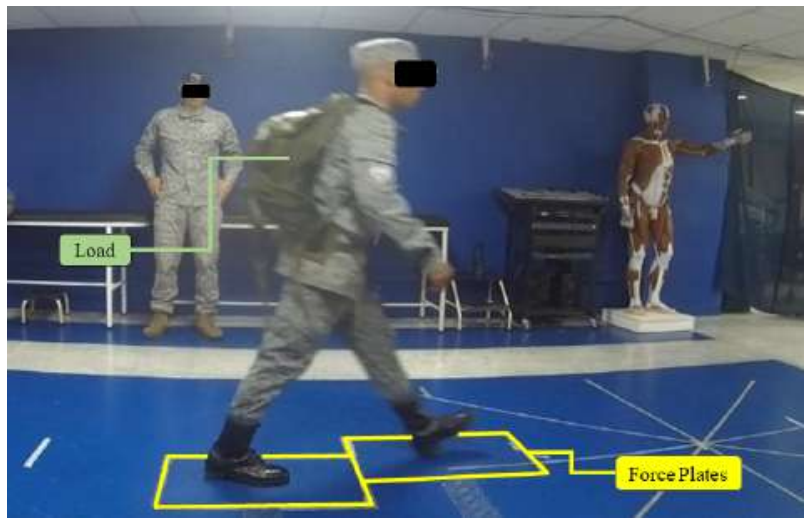

Figure 9 Subject training during walking test to capture kinetic data

were performed on four subjects to measure the VGRF with the conventional military backpack and the load carriage system prototype (Figure 12). The purpose was to establish a contrast between both systems which resulted in lower ground reaction forces while walking with the load. The Total Vertical Reaction Force (TVGRF) is obtained by adding the VGRF of each foot.

On average, the prototype showed a decrease in the maximum forces acting on the carrier going from 1269.9 $\mathrm{N}$ to $1193.7 \mathrm{~N}$ compared to the conventional military backpack, as shown in Table 2. Three out of the four subjects saw a decline in the maximum strength related to the TVGRF when using the prototype, as shown in Figure 12.

Table 2 Values of the TVGRF peak forces for each condition

\begin{tabular}{lccc}
\hline & $\begin{array}{l}\text { MILITARY } \\
\text { BACKPACK } \\
\text { (N) }\end{array}$ & $\begin{array}{l}\text { PROTOTYPE } \\
\text { (N) }\end{array}$ & $\begin{array}{l}\text { WITHOUT } \\
\text { LOAD } \\
\text { (N) }\end{array}$ \\
\hline Minimum & 1161.167 & 1097.1 & 949.206 \\
Maximum & 1480.694 & 1384.064 & 1105.595 \\
Rank & 319.527 & 286.964 & 156.388 \\
Mean & 1269.946 & 1193.755 & 1021.757 \\
$\begin{array}{l}\text { Standard } \\
\text { deviation } \\
\text { Variation } \\
\text { coefficient }\end{array}$ & 148.318 & 130.151 & 66.077 \\
\hline
\end{tabular}

\section{Discussion}

A few years ago, suspended-load carriage systems were introduced. While some of them showed a reduction in the acceleration forces generated by the load, others showed a significant increase. This response is related with the mechanical characteristics of the suspension system. In 


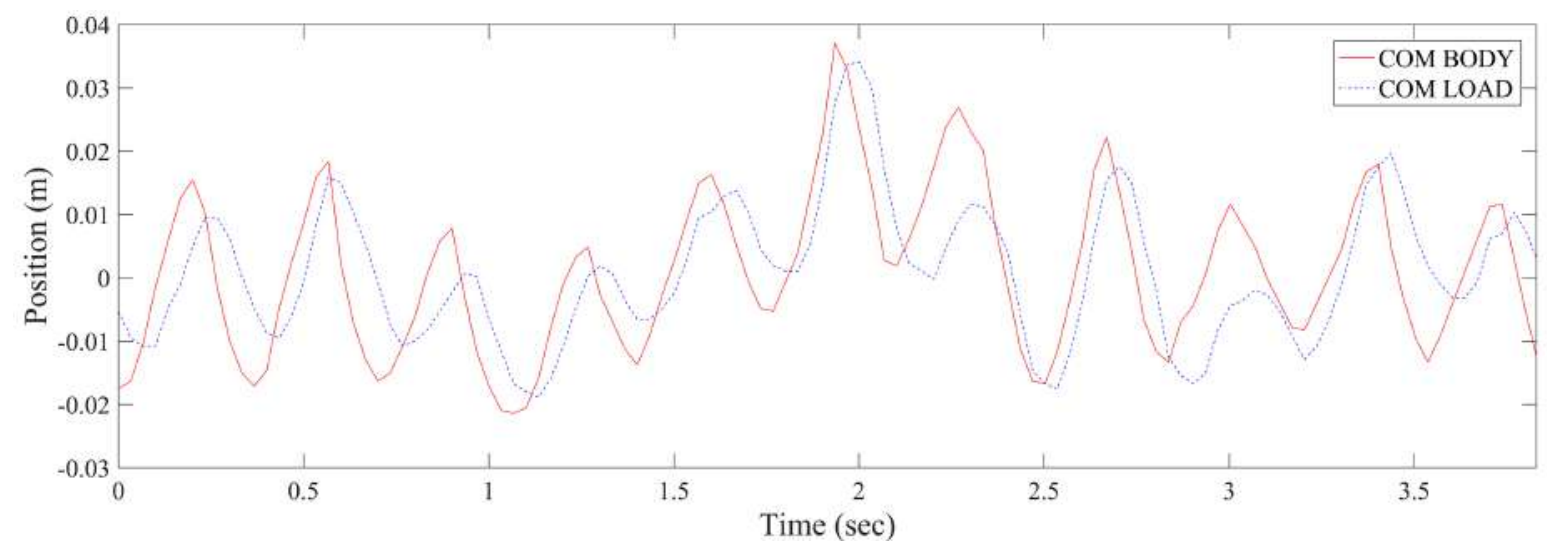

Figure 10 Vertical excursions for load and carrier at a speed of $1.5 \mathrm{~m} / \mathrm{s}$ $\mathrm{v}=1.5 \mathrm{~m} / \mathrm{s}$

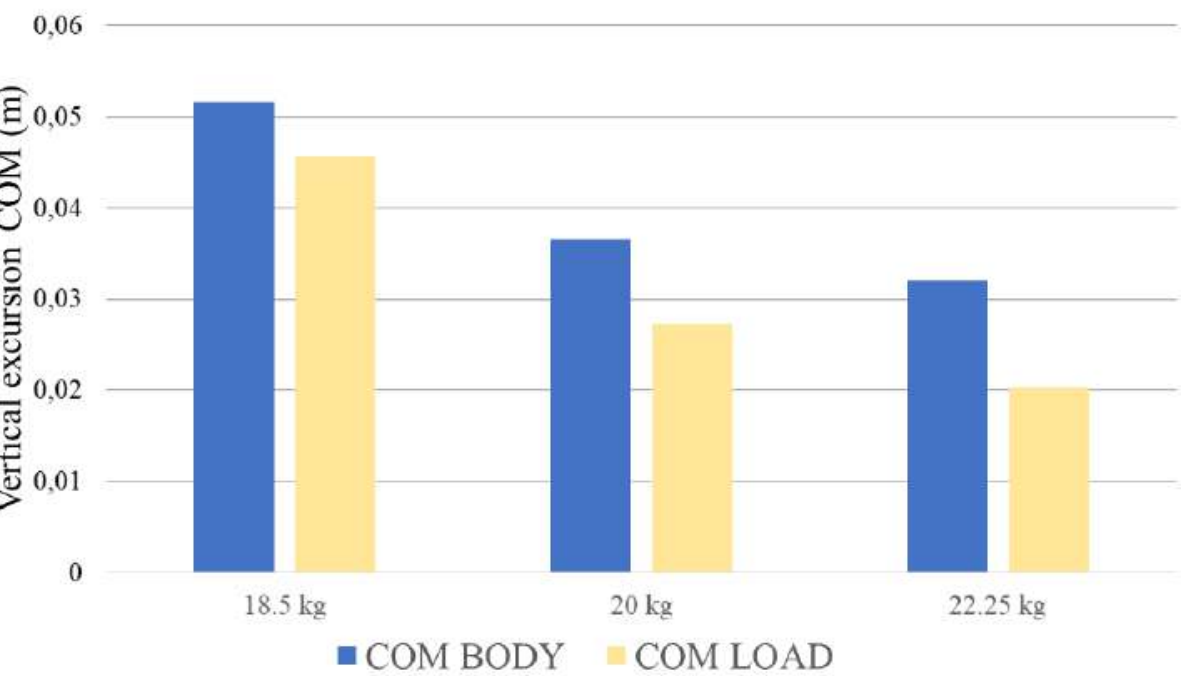

Figure 11 Amplitude of the vertical COM excursion for different masses with one subject

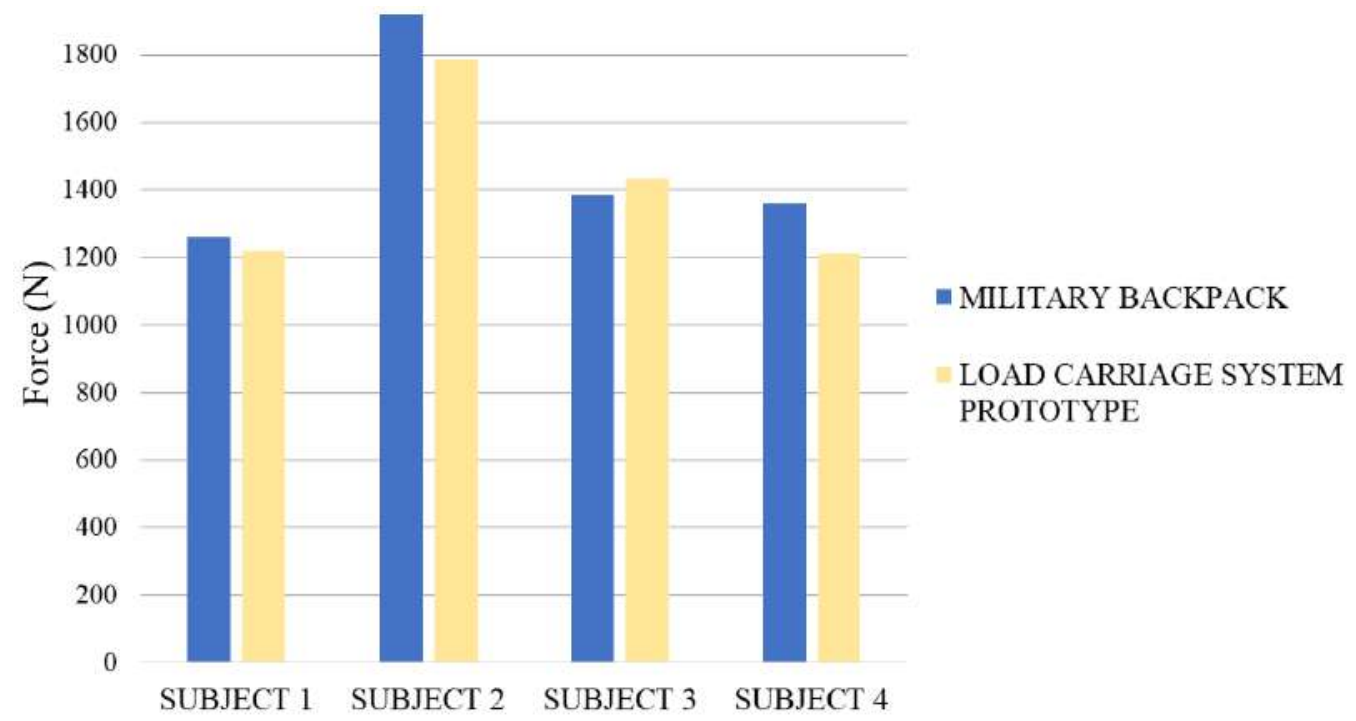

Figure 12 Total vertical ground reaction force (TVGRF) for each subject 
this project, a series of concepts were extrapolated, as the result of various investigations, and applied to the design of a load carriage system in the form of a military backpack. It considers the requirements of the target population comprised of Colombian infantry soldiers.

Regarding the vertical excursion of the load compared to the vertical excursion of the COM of a walking person, the prototype complied with the objective of reducing the vertical displacement of the load as well as the TVGRF. This can be attributed to the mechanical characteristics of the suspension system, derived from the Ackerman and Seipel mathematical model [10] and represented by the suspension setting consisting of a spring and a parallel gas damper, which had not been used in previous works. During the simulation tests of this model, it was determined that the elastic constant of suspension does not affect the vertical displacement of the load as much as the damping coefficient.

It can be noted that the simulation and test results were correlated, both showing $25 \%$ reduction in amplitude as well as a $90^{\circ}$ phase shift. The natural frequency of the mechanical suspension for the $20 \mathrm{~kg}$ mass is 7.071 $\mathrm{rad} / \mathrm{s}$, while the running frequency for the $1.5 \mathrm{~m} / \mathrm{s}$ speed is $12.4 \mathrm{rad} / \mathrm{s}$. Hence, Equation 5 is satisfied, since the natural frequency of suspension is significantly lower than the running frequency. This explains the decrease in the amplitude of the vertical excursion of the load as well as the phase shift between the relative movement of the load and the movement of the carrier.

The characterization of the mechanical suspension can be considered adequate, since the results exhibit an underdamped behavior, as seen in other suspension settings [11, 12]. Furthermore, the results are consistent with the model developed by [10], where the vertical excursion of the load is reduced to a greater extent by increasing the mass of the load and the moving speed and decreasing the damping of the suspension system. To obtain a complete decoupling of the movements of the load and the carrier COM, the damping factor and the elastic constant must be reduced even further. This decoupling leads to a significant decrease in the oscillation amplitude of the load and thus, a greater decrease in the forces acting upon the carrier as well as lower energy consumption.

During the experimental tests carried out to measure the GRF, a $20 \mathrm{~kg}$ load was used, which is not an accurate depiction of the loads normally carried by Colombian infantry soldiers. This weight was chosen because the ergonomic standard of military use states that loads of more than $35 \mathrm{~kg}$ should not be transported [12]. Another reason is that the first alpha prototype was purely developed for investigative and experimental purposes.

Regarding the maximum value of the TVGRF, there was a reduction of approximately $76 \mathrm{~N}$ with the prototype compared to the military backpack. This could offer benefits in terms of the reduction of musculoskeletal injuries caused by carrying loads. The data in Table 2 shows a wider range and standard deviation in the maximum strength of the military backpack, which seems to indicate that the variability in data is greater. This is confirmed by a variation coefficient of 0.116 while the maximum forces measured for the prototype are more homogeneous, with a variation coefficient of 0.109 .

The behavior of the VGRF is generated by the period after the heel touches the ground and the toes take off [3]. The results obtained from both force plates show that the TVGRF was reduced in three out of four participants. This could be explained by the oscillating movement of the load, since one of the two VGRF peaks can rise during contact with one force plate while the remaining peak is decreased in the other plate.

While this study revealed some interesting results, it had some limitations. In the construction process of the prototype, the suspension was limited to commercial shock absorbers, which caused that the tests could not include different damping coefficients. Therefore, it is recommended to use shock absorbers that can be calibrated with predetermined values. The experiments were carried out within a controlled environment, i.e. on flat ground at a constant speed. It would be interesting to take the experiment to the field and adjust the mathematical model by adding certain variations to represent environments that are more realistic.

\section{Conclusions}

It can be concluded that the design of the load carriage system and the manufacturing process were adequate. The device was validated with experiments which are evidence of a well-thought design process that complies with the goals set for the project. The prototype is able to reduce the vertical excursion of the load while walking as well as the maximum reaction force generated by the action of the load on the carrier.

This study provides insights related to the different types of suspension that seek to diminish backpack movement without affecting gait performance. The conducted experimental tests were part of a pilot study contributing to scientific and military development in Colombia. Therefore, there is a need for a much more complete study in which a greater number of variables are evaluated. Tests should be carried out on target 
populations with larger samples, comprised by Colombian infantry soldiers.

In conclusion, the device can help with load carriage, by decreasing the maximum reaction forces. Research must be continued on this field including the study of other possible configurations of load suspension systems. A low damping factor can completely decouple the vertical movement of the load from the vertical movement of the COM of a walking person.

Regarding future work, it could be useful to study different load suspension techniques with an understanding of feasible ergonomics. These efforts should aim at improving the biomechanics of the soldier, a scarcely studied area in Colombia.

\section{References}

[1] J. J. Knapik, K. L. Reynolds, and E. Harman, "Soldier load carriage: Historical,physiological,biomechanical, and medical aspects," Mil. Med., vol. 169, no. 1, January 2004. [Online]. Available: https: //doi.org/10.7205/milmed.169.1.45

[2] E. Harman, K. Hoon, P. Frykman, and C. Pandorf, "The effects of backpack weight on the biomechanics of load carriage," Army Research Institute of Environmental Medicine Military Performance Division, Natick, U.S., Tech. Rep. ADA377886, May 2000.

[3] S. A. Birrell, R. H. Hooper, and R. A. Haslam, "The effect of military load carriage on ground reaction forces," Gait Posture, vol. 26, no. 4 , October 2007. [Online]. Available: https://doi.org/10.1016/j.gaitpost. 2006.12.008

[4] J. F. Seay, "Biomechanics of load carriage," in The Mechanobiology and Mechanophysiology of Military-Related Injuries, A. Gefen and Y. Epstein, Eds. New York, USA: Springer, 2016, pp. 71-106.

[5] S. A. Gard, S. C. Miff, and A. D. Kuo, "Comparison of kinematic and kinetic methods for computing the vertical motion of the body center of mass during walking," Hum. Mov. Sci., vol. 22, no. 6, April 2004. [Online]. Available: https://doi.org/10.1016/j.humov.2003.11.002

[6] T. W. Huang and A. D. Kuo, "Mechanics and energetics of load carriage during human walking," J. Exp. Biol., vol. 217, no. 4, February 2014. [Online]. Available: https://doi.org/10.1242/jeb. 091587
[7] L. C. Rome, L. Flynn, and T. D. Yoo, "Rubber bands reduce the cost of carrying loads," Nature, vol. 444, pp. 1023-1024, 2006.

[8] M. Foisssac, G. Y. Millet, A. Geyssant, P. Freychat, and A. Belli, "Characterization of the mechanical properties of backpacks and their influence on the energetics of walking," J. Biomech., vol. 42, no. 2, January 2009. [Online]. Available: https://doi.org/10.1016/j. jbiomech.2008.10.012

[9] J. B. Saunders, V. T. Inman, and H. D. Eberhart, "The major determinants in normal and pathological gait," J Bone Joint Surg Am., vol. 35-A, no. 3, pp. 543-558, Jul. 1953.

[10] J. Ackerman and J. Seipel, "A model of human walking with an elastically-suspended load," J Biomech., vol. 47, no. 8, June 032014. [Online]. Available: https://doi.org/10.1016/j.jbiomech.2014.03.016

[11] X. Xu, "An investigation on the interactivity between suspended-load backpack and human gait," PhD dissertation, Department of Industrial and Systems Engineering, North Carolina State University, Raleigh, EE.UU, 2008.

[12] N. K. Putra, Suprijanto, and A. B. Sriwarno, "Dynamic modeling and simulation of the suspended-load backpack to obtain optimal suspension parameters and reducing effect of ground reaction force," in $6^{\text {th }}$ World Congress of Biomechanics (WCB 2010), Singapore, Asia, 2010, pp. 111-114.

[13] M. J. Atherden, "Formula sae shock absorber design," M.S. thesis, School of Engineering. The University of Queesnland, St Lucia, Australia, 2004.

[14] R. Ávila, L. R. Prado, and E. L. González, Dimensiones antropométricas de la población latinoamericana, 2nd ed. Guadalajara, México: Universidad de Guadalajara, Centro de investigaciones en ergonomia, 2007.

[15] J. Park, "Design of the second spine: a secondary pathway to transfer loads from the shoulders to the pelvis," in ASME 2013 International Design Engineering Technical Conferences and Computers and Information in Engineering Conference, Portland, Oregon, USA, 2013, pp. 4-7.

[16] (2018) Materials information resource. Material Property Data. Accessed May. 2019. [Online]. Available: https://bit.ly/2WWRqbl

[17] (2018) Proffessional 3D printing made accesible. materials. Ultimaker. Accessed May. 2019. [Online]. Available: https: //bit.ly/2Y401cd

[18] F. Multon and A. H. Olivier, "Biomechanics of walking in real world: Naturalness we wish to reach in virtual reality," in Human Walking in Virtual Environments: Perception, Technology, Applications, F. Steinicke, Y. Visell, J. Campos, and A. Lécuyer, Eds. New York, USA: Springer, 2013, pp. 55-77. 